\title{
Cognitive Fluency: High-Level Processing Dynamics in Art Appreciation
}

\author{
Benno Belke and Helmut Leder \\ University of Vienna
}

\author{
Tilo Strobach \\ Ludwig-Maximilians-Universität München
}

\author{
Claus Christian Carbon \\ University of Bamberg
}

\begin{abstract}
Based on findings that fluency of mental operations is hedonically marked and associated with more favorable evaluations of the processed target (Reber, Schwarz, \& Winkielman, 2004a; Winkielman, Schwarz, Fazendeiro, \& Reber, 2003) we investigated the contribution of such fluency effects for aesthetic appreciation. Using bogus titles that either facilitated or hindered semantic processing of paintings, fluency was investigated for higher-order cognitive operations on the level of meaning assignment. A cross-modal conceptual priming procedure was used, in which semantically related or unrelated titles, or "no-title" letter strings preceded the presentation of paintings with different degrees of visual abstraction. Results were in accordance with a fluency-affect-liking hypothesis. Related titles produced highest appreciation followed by no titles and unrelated titles conditions. This effect was moderated by the degree of abstraction of the paintings, with fluency effects especially prominent for representational paintings. Results indicated that aesthetic appreciation is partly grounded in the processing dynamics of the viewer and that the phenomenal experience of cognitive-fluency is an intrinsic source for the hedonic value of art.
\end{abstract}

Keywords: empirical aesthetics, processing fluency, dynamic appreciation, conceptual priming, visual art perception

Why do we find some things more aesthetically pleasing than others? In their comprehensive review of fluency-based effects, Reber, Schwarz, \& Winkielman (2004) proposed that aesthetic experience is in part a function of the perceiver's processing dynamics and suggested that "the more fluently perceivers can process an object, the more positive their aesthetic response" (page 364). The authors discussed variables that are known to affect aesthetic appreciation (such as stimulus repetition, figure-ground contrast, figural goodness, prototypicality, and symmetry) in an attempt to "trace their effects to changes in the underlying mental operations in the processing of an artwork" (p. 364). Specifically, it was assumed that processing fluency is itself hedonically marked, and subjectively experienced as positive and aesthetically pleasing (Winkielman \& Cacioppo, 2001). These fluency-based affective reactions, in turn, are assumed to feed into judgments of

This article was published Online First October 11, 2010.

Benno Belke and Helmut Leder, University of Vienna, Faculty of Psychology, University of Vienna, Vienna, Austria; Tilo Strobach, Ludwig-Maximilians-Universität München, Department of Psychology, München, Germany; and Claus Christian Carbon, University of Bamberg, Department of Psychology, Bamberg, Germany.

This research was supported by a grant to Helmut Leder from the Deutsche Forschungsgemeinschaft (DFG), SFB626, and by a grant to Helmut Leder and C. C. Carbon from the FWF (Austrian Science Fund; P18910). We thank Lisa Smith for valuable comments, as well as Sofia Tidman and Pablo Tinio for proofreading the manuscript.

Correspondence concerning this article should be addressed to Benno Belke, Faculty of Psychology, University of Vienna, Liebiggasse 5, 1010 Vienna, Austria. E-mail: benno.belke@gmail.com aesthetic appreciation because "people draw on their subjective experience in making evaluative judgments" (Reber et al., p. 366). Of note, Reber et al. (2004a) proposed that such experiential, fluency-based affective reactions are not a function of stimulus attributes but can be observed when fluency of processing is enhanced through variables that only affect the dynamics of processing a stimulus. This idea is grounded on well-established findings that recognition speed as well as evaluations are influenced by variables such as exposure duration, exposure frequency, and perceptual priming (e.g., Bornstein, 1989; Winkielman et al., 2003). Thus, rather than assigning aesthetic pleasure to objective stimulus features per se, they suggested that aesthetic pleasure might be based on the processing experience of the perceiver.

Although fluency presumably characterizes mental processing occurring at different stages (Reber et al., 2004), most studies related to artworks focused on perceptual features and perceptual fluency. Perceptual fluency concerns "the ease of identifying the physical identity of the stimulus" (Reber et al., 2004, p. 366) and depends on early automatic and implicit processing levels. It is influenced by variables such as repetition, figure ground contrast, grouping, perceptual priming, clarity, symmetry or presentation duration. (Leder, Belke, Oeberst \& Augustin, 2004; Reber, Winkielman, \& Schwarz, 1998; Reber et al., 2004a). However, art and particularly modern and contemporary art often convey ideas and concepts and therefore stimulate and require a particular search for meaning (Dewey, 1934), cognitive orientation, and interpretation (Kreitler \& Kreitler, 1972; Leder et al., 2004; Martindale, 1984; Millis, 2001; Parsons, 1987). Accordingly, the idea of a higherorder processing fluency-on the level of meaning assignment, stimulus interpretation and cognitive evaluation-seems particu- 
larly important for modern and contemporary art, which often provokes processing of conceptual, complex, and ambiguous information to be experienced as aesthetically pleasing. Therefore, the processing fluency of artworks often requires specific 'topdown' knowledge of what the artwork represents or is about and also involves style-based information related to how the content is visually represented (e.g., Belke, Leder, Harsanyi, \& Carbon, 2010). In line with these considerations, Reber et al. (2004a) proposed that their fluency approach also accounts for conceptual fluency of higher-order cognitive processing.

Generally, the concept of higher-order processing fluency is understood as the "ease of mental operations concerned with stimulus meaning and its relation to semantic knowledge structures" (Winkielman et al., 2003, p. 366). Such high-level processing fluency is associated with "progress toward successful recognition of the stimulus, error free processing, or the availability of appropriate knowledge structures to interpret the stimulus" (Winkielman, 2003, p. 366; for a more detailed discussion see Reber, Wurtz, \& Zimmermann, 2004; Whittlesea, 1993). The experience of cognitive-fluency is therefore directly related to parameters of processing speed, mental effort, and coherence of processing.

Leder et al. (2004) have included similar mechanisms in their integrative framework model of aesthetic experiences, particularly for the appreciation of modern and contemporary art. Central to the present study is the assumed affective evaluation and self-monitoring by the perceiver. Subjective "success" (or enhanced progress) on each processing stage is thought to provide an affectively positive and self-rewarding experience that constantly changes the development of an overall affective state (referred to as "aesthetic emotion"). It is important that the outcome of this affective evaluation can be constantly accessed by the perceiver, and is a potential source of information for the aesthetic appreciation of the artwork. According to Leder et al.'s (2004) model, processing based affective reactions could occur during early automatic and implicit processing stages, as well as during later higher-order stages of "explicit classification" (e.g., object and style recognition), "cognitive mastering" (e.g., finding meaning) as well as self- and stimulus-related evaluation (e.g., interpreting the artwork in terms of declarative knowledge structures). In the model's hierarchy, later higher-order processing stages can override previous stages before feeding into an aesthetic judgment. It is reasonable to assume that affective reactions based on cognitive-fluency may outweigh affective reactions based on perceptual fluency. Different to Reber et al. (2004a), the model also discusses the occurrence of affective marking resulting form "unsuccessful" (hindered) processing of art, which is supposed to result in less favorable appreciation. Similar to appraisal theories of emotions (e.g., Silvia, 2005; Scherer, 2003) the model directly links the affective evaluation of the stimulus target to the underlying cognitive processing dynamics. For example, displeasure and low appreciation could result if a satisfactory understanding an artwork cannot be achieved, or if adequate top-down information about the concept and meaning are not available.

Why might fluency be hedonically marked? As one explanation, Winkielman et al. (2003) suggested that fluency might serve as a cue to cognitive progress and might elicit affective responses as a kind of feedback about the underlying cognitive operations: "specifically highly fluent (fast, easy, coherent) processing tends to be indicative of progress towards successful recognition and interpre- tation of the target [...] if such progress is experienced as rewarding, it may motivate bringing the cognitive activity to completion" (p. 196). Moreover, easy processing might be pleasant because it indicates the availability of appropriate knowledge structures to deal with a current situation (Schwarz, 1990). Artworks may tap into such affective mechanisms that presumably originally evolved to serve a cognitive capacity in other contexts (Russell, 2003). This idea is in line with Bartlett's (1932) concept of "effort after meaning," a general tendency to make sense of one's perceptions by setting them in the context of past experiences (Cupchik, 1992). According to Russell (2003) such a tendency "ties in with evolutionary theories of mind that emphasize the adaptive, functional capacity of the brain for classifying sensory input by assimilating it into existing schemata, and the reinforcing consequences of this classificatory process" (2003, p. 100). If such an evolutionary formed cognitive tendency is particularly challenged by an artwork (e.g., through semantic ambiguity, stylized representation, or features that disrupt perceptual processing routines) the experience of its completion might be hedonically marked to a considerable extent. This affective dimension of "cognitive mastery" an artwork could explain the self-rewarding and reinforcing qualities of aesthetic experiences, and why artworks have hedonic value. This is in accordance for example, with Ramachandran and Hirstein's (1999) hypothesis that perceptual problem solving is selfrewarding and with findings that understanding of an artwork results in the activation of the rewarding centers in the brain as assumed by Maffei and Fiorentini (1995) and Zeki (1999).

However, as manipulations of cognitive-fluency are not the only means to low or high levels of aesthetic appreciation, it is assumed that cognitive-fluency is a contributor to aesthetic appreciation that presumably competes with processing of feature-based declarative information, and collative and psycho-physiological variables (Berlyne, 1971). Aesthetic appreciation is therefore likely to be influenced by a number of other factors such as style, subject matter, color, and skill of the painter (Russell, 2003) as well the perceiver's personal taste. Particularly, if the increment in cognitive-fluency produced by additional information, such as titles, would be relatively small, fluency-based effects might be swamped by these other influences. In line with these considerations, fluency proponents distinguish evaluative judgments based primarily on experiential information (e.g., the person's feelings or phenomenal experiences), from evaluative judgments based primarily on declarative information (e.g., features of the target; for a review see Schwarz, 1998).

A further boundary condition for our fluency assumption is that the influence of fluency on aesthetic appreciation might depend on the mode of art reception, which in turn is related to the level of art-expertise. Cupchick and Laszlo (1992) distinguished a "pleasure-based" from a "cognitive-based" mode of art. They claimed that art naïve persons refer stronger to a direct emotional mode of reception, while art experts depend more on a cognitive mode of reception. It is seems likely that a pleasure-based reception is associated with an affect infusion or affect as information heuristic (Schwarz \& Clore, 1983), in which the aesthetic evaluation is grounded on how the perceiver feels about the target. Thus, fluency may exert its greatest impact on appreciation in a pleasurebased mode of processing, which is more likely for art novices than art trained observers. 
Empirical evidences for a cognitive-fluency-evaluation link can be drawn from studies that employed manipulations designed to influence high-level stages of processing, concerned with identifying the meaning of the stimulus. One line of research is based on semantic and cross-modal priming procedures (Reber et al., 2004a; Winkielmann et al., 2003). In this priming procedure, participants were initially exposed to stimuli primes in one symbolic form (e.g., words) and subsequently respond to stimuli targets that were presented in a different form (e.g., pictures). Winkielmann et al. (2003) reported such studies in which a letter string served as the manipulation of conceptual fluency: "Some pictures were preceded by matched words (e.g., word "dog" paired with a picture "dog"), introducing the highest level of fluency. Other pictures were preceded by associatively related words (e.g., word "key" paired with a picture "lock"), introducing a medium level of fluency. Yet other pictures were preceded by unrelated words (e.g., word "snow" paired with a picture "desk"), introducing the lowest level of fluency." According to the authors "results showed a robust effect of conceptual fluency on participants' evaluation of the target pictures [. . .] Pictures preceded by matching words were liked significantly more than pictures preceded by related words, which in turn were liked significantly more than pictures preceded by unrelated words" (p. 206). However, these studies were conducted with rather simple non-art stimuli and fluency explanations might have restrictions when conclusions are drawn for art, and particularly modern art.

Other evidence for the effects of high-level fluency on aesthetic evaluation comes from studies that have manipulated information about an artwork available to the viewer. In these studies semantic information in the form of titles was added to artworks (Franklin, Becklen, \& Doyle, 1993; Millis, 2001; Leder, Carbon, \& Ripsas, 2006; Russell \& Milne, 1997), or presented as short texts surpassing what can be readily inferred from the artwork (Russell, 2003; Belke, Leder, \& Augustin, 2006). Millis (2001) found that titles increased aesthetic experiences only when they contributed to rich and coherent representations. Russell (2003) reported an increase in the hedonic value of a painting associated with information that aids its interpretation and heightens its meaningfulness. Russell concluded that "some of the pleasure derived from looking at a painting stems from successfully interpreting it and picking up the artist's message" (2003, p. 99).

We propose that such findings can be interpreted in light of a cognitive-fluency hypothesis, wherein the fluency of high-level operations concerned with the processing of an artwork is affectively marked and influences the aesthetic evaluation of the artwork. Changing the ease of finding a meaning in an artwork should therefore systematically affect its appreciation.

\section{The Present Study}

In the present study, we investigated, whether a perceiver's aesthetic appreciation is influenced by the affective correlates of the underlying high-level processing fluency. We applied a cross modal conceptual priming method in which the ease of semantic processing of paintings was manipulated by preceding titles. Moreover, we investigated not only positive hedonic effects due to increased fluency but also effects when semantic processing was hindered. This would reveal that aesthetic appreciation could be influenced in a positive as well as in a negative direction, varying with the underlying cognitive processing characteristics of the viewer.

As the main manipulation, we presented depictions of real artworks of three artistic styles, which were preceded by semantically related, nonrelated titles or no-titles (presented as the letter string "no title"), thereby introducing three different levels of processing fluency. A cross modal priming method is based on the assumption that the encoding of a meaningful stimulus is facilitated by the prior presentation of a semantically related item (Collins \& Loftus, 1975; Schvaneveldt, Meyer, \& Becker, 1976). Therefore, it was expected that additional information preceding picture presentation trigger prior activation of the corresponding semantic network. Such a pre-activation of semantic features, which is critical to artwork identification and interpretation, should result in greater processing facilitation and a stronger experience of cognitive-fluency. This idea is in accordance with broad empirical evidence in that semantically related word primes facilitate the processing of pictures in tasks involving picture categorization and naming, (e.g., Alario, Segui, \& Farrand, 2000; Glaser \& Düngelhoff, 1984; Smith, Meiran, \& Besner, 2000). According to Millis (2001) descriptive titles can "disambiguate references and events during encoding, making the representation coherent" and thereby offer an "initial interpretation and limit elaborative processing by constraining interpretations placed upon the artwork" (p. 320). Consequently, priming with semantically related or unrelated titles affects the accessibility of a coherent representation that is relevant for categorization and understanding of an artwork. Such a priming procedure therefore enables investigation of different levels of higher-order processing fluency as cognitive operations involved in classification and finding a meaning are concerned.

In this study, made-up titles were presented to ensure a high degree of semantic correspondence, and thereby to increase the possibility of inducing cross-modal priming effects. Because for an artwork a preexisting and unambiguous title is often not at hand in the same way as a category name for a real-world object exists (e.g., the word "table" for a picture of a table) a pre-study was carried out in which participants rated a set of several pregenerated title-painting combinations in respect to perceived correspondence. Thus, only title-painting pairs that were perceived as sufficiently "matching" were selected for the main experiment.

To test fluency manipulations on a comprehensive range of art styles, we included representational, cubist, and abstract paintings. These may be differentially susceptible to the semantic priming method. Representational paintings might be particularly prone to fluency manipulations, as titles can refer to a specific representational content in an unambiguous manner. Consequently, titles can trigger a coherent representation by disambiguating references and constraining interpretations, and thereby facilitate or inhibit the subsequent processing of the painting. In contrast, abstract paintings by definition have no representational content and might therefore more likely allow for the integration of a broad range of additional semantic information. It is highly vague what the artwork represents and is about, thus title primes might not facilitate access to specific representations in the same manner. In between are semiabstract art-styles such as Cubism, which vary in the amount that the representation of a recognizable object can be accessed (Hekkert, 1995; Kuchinke, Trapp, Jacobs, \& Leder, 2009), but usually comprise of identifiable, although often distorted objects.

A within-subjects design was applied to test these hypotheses. This decision was based on findings and suggestions by Russell (2003), 
who revealed effects of extra titles on the hedonic value of paintings only when using a within-subjects design but not in a betweensubjects design. He concluded that a between-subjects design is relatively insensitive to the effects of different evaluative conditions.

To summarize, in the present study we attempted to clarify the status of cognitive-fluency in aesthetic experiences by investigating whether the experiential information of processing ease contributes to the aesthetic appreciation of a painting. We applied a cross-modal priming design in which semantically related, unrelated, and no-title priming conditions were compared. We expected that preceding titles would be able to facilitate or inhibit the ease of subsequent cognitive operations involved in the initial categorization of and the search for meaning in the paintings. We predicted that the appreciation of paintings in the related title conditions would be higher than in the neutral and unrelated title conditions, respectively. These predictions were tested in three different sets of paintings (representational, cubist, and abstract) that varied in their degree of visual abstraction.

\section{Method}

\section{Selection of Stimuli in a Pre-Study: Matching Agreement Task}

Title-painting combinations were selected based on a pre-study. In a group Session 24 participants were presented a set of 41 reproductions of paintings from three styles (16 representational paintings, 13 cubist paintings, 12 abstract paintings). Each painting was paired with three alternative titles that were previously made up (for each painting) by a group of four psychology students. Participants of the pilot study were instructed to rate the perceived match between each of the four titles and the specific painting on a 7-point scale (1-not at all related to 7-perfectly related). Paintings were presented for approximately 30 seconds each and the corresponding alternative titles were rated subsequently. For the Experiment 24 title-paintings combinations (eight representational, eight cubist, eight abstract), with the highest means in ratings of titlepicture match were selected as stimuli. The Appendix shows the complete list of selected paintings, titles, and means of perceived match of title-painting combinations, with a general mean of $M=$ $5.30(S D=.522$, range: $4.58-6.33)$.

A further analysis revealed systematic differences in the semantic determinacy of the 24 paintings depending on their degree of realism. A one-way analysis of variance (ANOVA) based on ratings of title-picture match was performed with abstraction (abstract, representational, cubist paintings). This analysis showed a main effect of abstraction, $F(2,21)=16.11, p<.001, \eta_{p}^{2}=.61$. Unpaired $t$ tests between the three sets of paintings showed significant higher means on perceived title-picture match for representational $(M=5.83, S D=.42)$ than for cubist $(M=5.19, S D=$ $.33)$ and for abstract stimuli $(M=4.87, S D=.26), t(14)>3.36$, $p<.01$. The difference between cubist and abstract stimuli was also significant, $t(14)=2.17, p<.05$. These results indicated a natural confound between the degree of abstraction and the perceived semantic match to titles. While titles could refer to a depicted content in representational paintings in a more unambiguous manner, semantic correspondence was perceived as more vague for cubist and abstract paintings.

\section{Participants}

Twenty undergraduate psychology students from the Freie Universität Berlin were tested individually (17 females, $M=25.7$ years $[S D=7.09)$, range $=20-46$ ). Participants volunteered for partial course credit. All participants had normal or corrected-tonormal vision. They were naïve to the purpose of the experiment.

\section{Apparatus and Stimuli}

Twenty-four paintings (eight representational, eight cubist, and eight abstract) were used as stimuli. There were three priming conditions: first, related title conditions with 24 "matched" titlepainting combinations; second, unrelated title conditions, in which the same 24 titles were consistently mismatched with a particular painting, resulting in 24 (fixed) "mismatched" title—painting combinations; and third, neutral conditions, in which the letter string "no title" was used as a nonspecific word prime. ${ }^{1}$ Stimuli were standardized to a size of $380 \mathrm{~cm}^{2}$ with $72 \mathrm{dpi}, 8$-bit, and a resolution of $1024 \times 768$ pixels. The experimental sessions were controlled using E-Prime on a PC-system.

\section{Procedure}

Participants were told that the study was concerned with emotional processes involved in the perception of paintings. At the beginning of the experiment, participants performed three practice trials. A practice trial consisted of each priming condition (related, unrelated, and neutral) with stimuli not used in the main experiment. Participants were instructed to rate the paintings on a 4-point Likert scale (1-I don't like the painting at all to 4-I like the painting very much). This scale was also used in the following test phase. The three training trials were in a random order and were not analyzed.

In the main experiment, the 24 stimuli were presented in each of the three priming conditions resulting in a total of 72 trials. To prevent a potential bias or confound of the initially shown title-painting combinations on subsequent experimental blocks that could have resulted from a within-subjects design (since each painting was shown with three different titles over the course of the experiment), style and title conditions were completely randomized. All trials were presented in one block. Priming conditions were balanced, with 24 trials in the related, unrelated, and neutral primes each. The whole session lasted approximately 35 minutes.

Each experimental trial started with a fixation cross presented at the center of the screen for $500 \mathrm{~ms}$. A word prime immediately followed at the same position for 2,000 ms. The word prime (either related, unrelated, or neutral title) was followed by a painting, which was presented for $1,000 \mathrm{~ms}$ at the center of the screen. Subsequently, a blank interval (representing a response screen) appeared, in which participants were asked to rate the paining ("How do you like the painting?") using a 4-point Likert scale (1-I don't like the painting at all, 2 -I don't like the painting, 3-I like the painting, 4-I like the painting very much). Response keys were

\footnotetext{
${ }^{1}$ It cannot be excluded that participants initially interpreted the "no title" prime as an actual title, which might have created some noise in the data The effect seemed to be of minor relevance, as the no title condition appeared repeatedly (24 times) and made it obvious that no specific painting is referred to.
} 
marked on the keyboard ( $\mathrm{Y}=1, \mathrm{C}=2, \mathrm{~B}=3, \mathrm{M}=4$ ). Participants were asked to provide their ratings spontaneously, accurately, and as fast as possible. If a rating was not given within the 5,000-ms response interval, the next trial was started. The end of each trial was marked by an interstimulus interval consisting of a blank screen for $3,500 \mathrm{~ms}$.

\section{Results and Discussion}

Liking ratings (sampled over participants) were analyzed as the dependent variable. The independent variables were condition (related, unrelated, neutral title primes) and abstraction (abstract, representational, cubist paintings) (Figure 1$)$. A two way $(3 \times 3)$ within-subjects ANOVA revealed main effects for condition, $F(2$, $38)=5.94, p<.01 \eta_{p}^{2}=.24$ and abstraction, $F(2,38)=15.67$, $p<.001, \eta_{p}^{2}=.45$, as well as a significant interaction, $F(4,76)=$ 3.96, $p<.01, \eta_{p}^{2}=173$. As expected, planned pairwise comparisons revealed higher liking ratings in the related $(M=2.55)$ than unrelated $(M=2.29, p<.01)$ and neutral title conditions $(M=$ $2.49,<.05)$. This pattern of results supports our cognitive-fluency assumption and suggests a hedonic marking of facilitated high-level processing in the related title conditions compared with negative affective marking based on a less cognitively fluent processing in the unrelated titles conditions. Means in the neutral conditions can be regarded as baseline ratings of appreciation for each painting.

In additional analyses the interaction between condition and abstraction was decomposed to reveal how the impact of title primes on appreciation was moderated by the degree of abstraction of the paintings. Three separate one-way repeated-measures ANOVAs with condition (related, unrelated, neutral) as the independent variable were performed for representational, cubist, and abstract paintings. Significant effects of condition were found for representational paintings, $F(2,38)=5.00, p=.01, \eta_{p}^{2}=.21$ and cubist paintings, $F(2,38)=11.29, p<.001, \eta_{p}^{2}=.37$. There was no effect of condition for abstract paintings, $F(2,38)=.87, p=$
$.43, \eta_{p}^{2}=.04$. Table 1 provides a detailed overview of priming effects on the three sets of paintings.

The strongest impact of fluency manipulation was clearly observable in representational paintings, for which data indicated a fluency effect in the predicted direction. Related titles eased subsequent semantic processing of the paintings, which was hedonically marked and induced higher judgments of liking. Consequently, unrelated titles produced less fluent processing of representational paintings, which lead to a decrease in ratings of liking. On the contrary, title primes had no observable effects on the appreciation of abstract paintings. Results for cubist paintings suggested a one-sided fluency manipulation. While data indicated a decreased cognitive-fluency in the unrelated title conditions, an enhancement of fluency could not be induced through related titles for this set of paintings.

Post hoc analyses of the main effect of abstraction revealed that representational paintings were in general preferred over cubist and abstract paintings. Bonferroni adjusted $(\alpha=.0167) t$ tests showed significant differences in liking between representational and abstract $(M=2.80, S D=.42$ vs. $M=2.09, S D=.50)$, $t(19)=-4.83, p<.001, d=1.55$, representational and cubist $(M=2.80, S D=.42$ vs. $M=2.43, S D=.47), t(19)=-2.70, p<$ $.01, d=.83$, and abstract and cubist paintings $(M=2.09, S D=$ .49 vs. $M=2.43, S D=.47), t(19)=3.56, p=.01, d=.71$. This confirms previous findings that artworks with more depictive, representational content are generally preferred over cubist and abstract paintings, by naïve perceivers (e.g., Cupchik, 1992). This could be due to the effect that preference for representational or semiabstract paintings has been found to be a positive function of their perceived meaningfulness (Martindale, Moore, \& Borkum, 1990) or their degree of photographic likeness (Hekkert \& van Wieringen, 1990).

A possible concern may be that participants, due to the withinsubjects design, were influenced by previous encounters with titles and results may have been influenced by cross-block reactivity

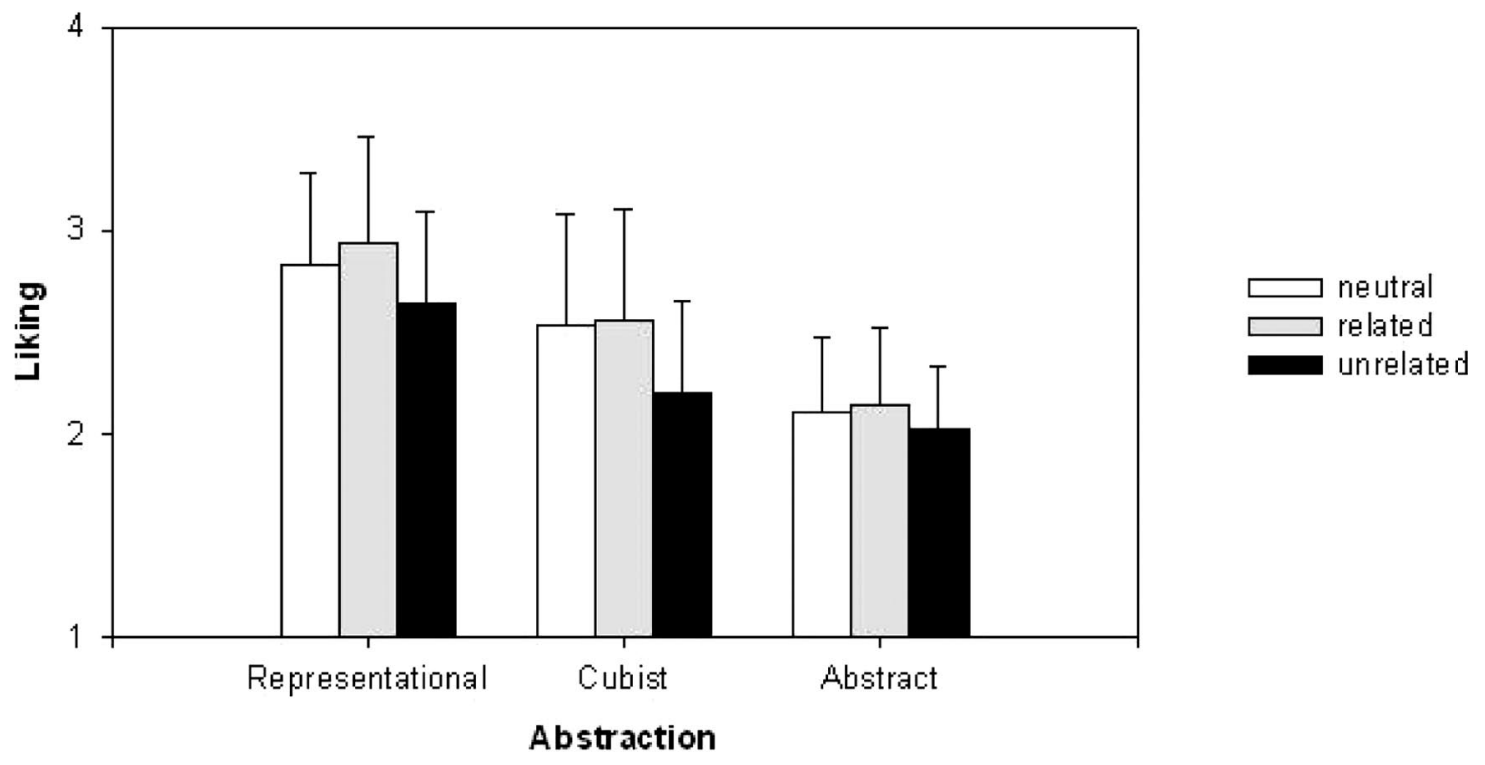

Figure 1. Ratings of Liking as a function of title-priming condition and abstraction. Bars indicate standard errors of the mean. 
Table 1

Detailed Comparisons of Liking Ratings for Priming Condition and Abstraction

\begin{tabular}{|c|c|c|c|}
\hline & Related & Unrelated & Neutral \\
\hline \multicolumn{4}{|l|}{ Representational paintings } \\
\hline Related $M=2.94, S D=.52$ & - & & \\
\hline Unrelated $M=2.64, S D=.49$ & $t(19)=2.35, p<.05, d=.58$ & - & \\
\hline Neutral $M=2.83, S D=.46$ & $t(19)=2.09, p<.05, d=.21$ & $t(19)=-2.05, p<.05, d=.40$ & - \\
\hline \multicolumn{4}{|l|}{ Cubist paintings } \\
\hline Related $M=2.56, S D=.55$ & - & & \\
\hline Unrelated $M=2.20, S D=.45$ & $t(19)=3.51, p<.01, d=.72$ & - & \\
\hline Neutral $M=2.54, S D=.54$ & $t(19)<1$ & $t(19)=-3.59, p<.01, d=.61$ & - \\
\hline \multicolumn{4}{|l|}{ Abstract paintings } \\
\hline Related $M=2.14, S D=.58$ & - & & \\
\hline Unrelated $M=2.03, S D=.40$ & $t(19)=1.18, p>.25$ & - & \\
\hline Neutral $M=2.11, S D=.64$ & $t(19)<1$ & $t(19)<1$ & - \\
\hline
\end{tabular}

(having seen the same painting in different priming conditions). Therefore, we carried out an additional analysis to check whether the pattern of results would change, if only the initial encounters with each painting (in one of the three priming conditions) were considered, and the two subsequent encounters for each painting (in the remaining priming conditions) were excluded. This ensured that the only trials analyzed were those, in which each participant saw each painting in only one specific priming condition. As a direct test, we included the factor encounter (initial primes vs. all primes) in a three way $2 \times 3 \times 3$ ANOVA with condition (related, unrelated, neutral title primes), and abstraction (abstract, representational, cubist paintings). Critically, no interactions between encounter and condition $F(2,28)<1$, or between encounter and abstraction, $F(2,28)<1$, nor a three-way interaction, $F(4,56)=$ $1.68, p>.17 \eta_{p}^{2}=.11$, was found. These findings suggested that cross-block reactivity did not influence results, and that participants responded similarly to manipulations of fluency in trials of first contact with a stimulus and subsequent contacts across the whole experimental session. Moreover, the pattern of results based for condition, $F(2,28)=4.20, p<.03 \eta_{p}^{2}=.23$ and abstraction, $F(2,28)=6.54, p<.01 \eta_{p}^{2}=.32$, replicated the findings above of two significant main effects. The interaction was marginally significant, $F(4,56)=2.43, p<.06 \eta_{p}^{2}=15$. $^{2}$

A main effect of encounter, $F(1,14)=5.00, p<.04 \eta_{p}^{2}=.26$, indicated a general tendency for higher appreciation when considering all trials as compared to a subset of trials with only initial encounters. Presumably, this increase of appreciation over repeated presentations of the paintings simply reflects a mere exposure effect based on increased exposure frequency.

\section{Conclusion}

The findings of this study are consistent with predictions from a fluency-liking approach and suggested that aesthetic appreciation is partly grounded in a perceivers' higher-order-processing dynamics. Changes in appreciation for paintings resulting from priming of semantically related, unrelated, and no titles hint at an affective marking mechanism of facilitated and obstructed processing on the level of meaning assignment and understanding. Results showed that this cognitive-fluency-liking relationship was moderated by the degree of abstraction of the paintings. Changes of appreciation for representational paintings confirmed our prediction of the hedonic effects of eased mental operations. Specifically, for representational paintings, related title primes presumably facilitated the subsequent semantic processing of the paintings, which lead to a more favorable aesthetic application. Results were also compatible with findings indicating that semantically related titles enhance positive emotional responses to art by making art more comprehensible (e.g., Millis, 2001; Russell \& Milne, 1997; Russell, 2003; Leder et al., 2006). In contrast, appreciation was low when finding a meaning was impeded through misleading titles, suggesting that a negative affective marking resulted from an obstructed flow of mental operations. This confirms our assumption of a two directional affective evaluation of a beholder's processing dynamics, which is based on monitoring the "success" of higher-order cognitive operations in aesthetic experiences (Leder et al., 2004). To our knowledge this is the first published study that provides direct empirical evidence for this key assumption of the Leder et al. (2004) model.

We found interesting that fluency manipulations for cubist paintings were restricted to decreases in appreciation in the unrelated conditions, which indicated displeasure resulting from obstructed processing. No priming effects were observed in the related title conditions. When there was ambiguity with what a painting represented, it was presumably easier for people to identify a mismatch between title and target painting (testing what a painting is not about) than a match (testing what the painting is about). This seems plausible since ambiguity of depicted content is particularly strong in cubist paintings (Kuchinke et al., 2009).

The lack of enhancement of aesthetic experience for abstract paintings through additional information is consistent with Russell and Milne's (1997) finding that titles do not increase the hedonic value of abstract paintings. When clear external references and a concrete representational content is missing, this may allow for numerous semantic interpretations and meaning assignments, thus extra semantic information does not induce substantial changes in processing fluency. However, results for cubist and particularly abstract paintings seemed at first to contradict our cognitivefluency hypothesis. It could be reasoned that the effects of addi-

\footnotetext{
${ }^{2}$ Please note that five participants were omitted from analysis due to missing values. Therefore, the statistical power is presumably lower compared to the above-described analyses.
} 
tional semantic information should be particularly prominent for paintings where prima facie meaningfulness is relatively low, and the information can make a significant contribution toward helping the viewer to achieve a satisfactory understanding or interpretation (Russel, 2003). Our data suggested the opposite. The assumption, that abstract art could bear more semantic discrepancy, while representational art produces a clearer match and mismatch with specific memory representations is supported by results of the pre-study. These indicated a natural confound between the semantic determinacy of paintings and its degree of abstraction.

However, results of an additional multivariate analysis of variance (not reported in the Results section), in which the ratings of cross modal match between each title and its corresponding painting were treated as a covariate (thereby statistically controlling the variance from differences in perceived match), did not reveal more prominent priming effects in abstract and cubist paintings. This suggested that the fluency manipulation, although presumably initially hedonically marked, competes with other apparently declarative, feature-based evaluation such as how well the painting is crafted, how original a painting is, and whether a painting is perceived as meaningful. As an alternative explanation, it seems therefore possible that fluency effects may have been attenuated or diminished for abstract and cubist paintings by later object-related declarative processing. This is consistent with the finding that the overall contribution of title primes for appreciation was small across all artistic styles compared to variations in appreciation between single paintings, which hints at multiple influences on aesthetic appreciation. In accordance with a fluency approach these results suggested that the experiential information of the viewer's processing ease is a contributor to the aesthetic appreciation of an artwork. Such phenomenal information may be used to evaluate the artwork but may also compete with processing of object-related and feature-based declarative information, so that fluency effects may have been attenuated or even outweighed by later evaluative processing in cases where the content is regarded for example, as not being original, meaningful or well crafted. This is in line with the assumption that processing fluency provokes an initial automatic affective reaction and that affective reactions to stimulus content can override "pure" fluency effects in subsequent processing stages (Reber et al., 2004). This might have prevented fluency effects from being stronger for cubist and abstract paintings, especially since participants consisted of a group of art naive viewers, which might have had strong concerns when evaluating abstract art.

The idea of competing experiential- and declarative-based affective reactions, as two main sources of information on which the appreciation of art is grounded, is also in line with findings summarized by Winkielman et al. (2003) that "highly familiar or simple stimuli may initially elicit a positive reaction because they can be processed with high fluency but may seem uninteresting and boring once their features are extracted and attended to" or vice versa "that people prefer novel, complex, and surprising stimuli over simple and familiar ones" (p. 210; for a more detailed discussion see Bornstein, Kale, \& Cornell, 1990; Cox \& Cox, 1988). Furthermore, this idea may offer an alternative explanation to Russell and Milne's (1997) finding that titles selectively increased meaningfulness of abstract paintings but did not affect their hedonic value. Later declarative-based evaluative processing might have simply attenuated the increased hedonic value elicited by titles. Therefore, as proposed by Winkielman et al. (2003), future studies should carefully distinguish fluency-based affective reactions from feature-based affective reactions as two separate sources of hedonic value of artworks.

Arguably, a limitation of this study may be that affective reactions were not obtained directly using psycho-physiological measures. Instead, we considered ratings of appreciation as indicative of affective correlates of cognitive-fluency. This is in line with claims that fluency-based affective reactions are reflected in judgments of aesthetic appreciation (e.g., Belke et al., 2006; Reber, Winkielman, \& Schwarz, 1998). Furthermore, the subjective experience of fluency is sometimes dissociated from the objective occurrence of fluency (see Winkielman et al., 2003 for a detailed discussion of such findings) and therefore not always measurable in behavioral data. Moreover, if the subjective fluency experience is based on the availability and appropriateness of knowledge structures to interpret a stimulus, as suggested by Schwarz (1990), it may not be reflected in measures such as reaction times, recognition speed, and galvanic skin response.

Although the effects of manipulating the processing ease of paintings were rather small, they seem to reveal a fundamental mechanism of affectively marking the cognitive-fluency of an aesthetic experience. It is important that the experimentally induced changes in appreciation resulted solely from changes in the processing dynamics of the viewer and were not based on alteration of features of the artworks or context of their reception. Therefore, the study provided evidence that phenomenal information about processing an artwork itself affects its aesthetic appreciation.

We propose that such high-level fluency effects might increase depending on the processing stage on which fluency occurs. Although the selection of titles based on a pilot study ensured a high degree of perceived title-painting correspondence this procedure lead to rather descriptive titles for representational paintings (e.g., "tobacco pipe," "oak tree in wide open space") for which fluency effects were most clearly observed. These descriptive titles offered an initial coherent representation and constrained alternative interpretations placed upon the artwork. Thus, titles may have facilitated semantic processing by enhancing recognition memory through eased categorization and coherent initial interpretation of depicted content. Since only art inexperienced participants had been tested, results are in accordance with a well-established finding that naïve perceivers respond strongly to realism in paintings, presumably as an indicator of perceived meaningfulness (e.g., Martindale, Moore, \& Borkum, 1990). Therefore, the classification of explicit content seems to be an important subprocessing stage for naïve perceivers and may account for changes in aesthetic appreciation observed in this study. It seems likely that elaborative titles, which might trigger enriched and alternative representations to what can be readily inferred from the artwork (Millis, 2001), provoke processing fluency effects based on later higher-order processing stages such as "cognitive mastering" and "evaluation" (Leder et al., 2004) and thereby increase the overall fluency experience further.

This assumption is further supported when presentation times of the paintings are considered. Participants were asked to rate the paintings as fast as possible. This resulted in an average evaluation time of less than five seconds, which means that these exceedingly complex stimuli were prevented from deeper elaboration in later cognitive stages, such as art- and self-related evaluations. Leder et 
al. (2006) found that for short presentation times (1 s), descriptive titles increased the understanding of artworks more than elaborative titles, whereas for medium presentation times (10 s), elaborative titles increased the understanding for artworks more than descriptive titles. They concluded that with artworks, a presentation time of around $10 \mathrm{~s}$ might be needed to assign a meaning beyond mere description. Therefore, it seems possible that longer evaluation/presentation times (combined with more elaborate titles) could further enhance cognitive-fluency effects. Future studies might systematically investigate fluency effects by systematically varying titles (e.g., descriptive and elaborative), and evaluation times in order to test different high-level processing stages involved in meaning assignment.

Based on results of this study, it cannot be excluded that similar findings could also be obtained with non-art stimuli. However, there are several possible explanations for why art is processed differently from other classes of objects. Examples include stylebased representation (e.g., Belke et al., 2010), semantic indeterminacy, and features that disrupt perceptual processing routines that are active in everyday perception. Therefore, artworks often provide a particular processing challenge, which is why we assume that cognitive-fluency-based affective reactions to artworks (indicating the successful cognitive mastery of the stimulus) may be even more pronounced. However, this assumption needs to be tested in future research.

To conclude, the present study extends our understanding of how high-level processing dynamics change they way we appreciate art. It reveals the importance to consider experiential information of a perceiver's higher-order processing fluency as one intrinsic source of hedonic value of art.

\section{References}

Alario, F. X., Segui, J., \& Ferrand, L. (2000). Semantic and associative priming in picture naming. Quarterly Journal of Experimental Psychology: Section A, 53, 741-764.

Bartlett, F. C. (1932). Remembering: A study in experimental and social psychology. Cambridge, UK: Cambridge University Press.

Belke, B., Leder, H., \& Augustin, M. D. (2006). Mastering style. Effects of explicit style-related information, art knowledge and affective state on appreciation of abstract paintings. Psychology Science, 48, 115-134.

Belke, B., Leder, H., Harsanyi, G., \& Carbon, C. (2010). When a Picasso is a "Picasso": The entry point in the identification of visual art. Acta Psychologica, 133, 191-202.

Berlyne, D. E. (1971). Aesthetics and psychobiology. New York: AppletonCentury- Crofts.

Bornstein, R. F. (1989). Exposure and affect: overview and meta-analysis of research, 1968-1987. Psychological Bulletin, 106, 265-289.

Bornstein, R. F., Kale, A. R., \& Cornell, K. R. (1990). Boredom as a limiting condition on the mere exposure effect. Journal of Personality and Social Psychology, 58, 791-800.

Collins, A. M., \& Loftus, E. F. (1975). A spreading-activation theory of semantic processing. Psychological Review, 82, 407-428.

Cox, D. S., \& Cox, A. D. (1988). What does familiarity breed? Complexity as a moderator of repetition effects in advertisement evaluation. Journal of Consumer Research, 15, 111-116.

Cupchik, G., \& Laszlo, J. (1992). Emerging visions of the aesthetic process: Psychology, semiology, and philosophy. New York: Cambridge University Press.

Cupchik, G. C. (1992). From perception to production: A multilevel analysis of the aesthetic process. In G. C. Cupchik \& J. Laszlo (Eds.),
Emerging visions of the aesthetic process: Psychology, semiology, and philosophy (pp. 61-81). New York: Cambridge University Press.

Dewey, J. (1943). The school and society. Chicago: University of Chicago Press.

Franklin, M. B., Becklen, R. C., \& Doyle, C. L. (1993). The influence of titles on how paintings are seen. Leonardo, 26, 103-108.

Glaser, W. R., \& Düngelhoff, F. J. (1984). The time course of picture-word interference. Journal of Experimental Psychology: Human Perception and Performance, 10, 640-654.

Hekkert, P. (1995). Artful judgements: A psychological inquiry into aesthetic preference for visual patterns. Unpublished doctoral thesis, Delft University of Technology.

Hekkert, P., \& van Wieringen, P. C. W. (1990). Complexity and prototypicality as determinants of the appraisal of cubist paintings. British Journal of Psychology, 81, 483-495.

Kreitler, H., \& Kreitler, S. (1972). Psychology of the arts. Durham, NC: Duke University.

Kuchinke, L., Trapp, S., Jacobs, A. M., \& Leder, H. (2009). Pupillary responses in art appreciation: Effects of aesthetic emotions. Psychology of Aesthetics, Creativity and the Arts, 3, 156-163.

Leder, H., Belke, B., Oeberst, A., \& Augustin, D. (2004). A model of aesthetic appreciation and aesthetic judgments. British Journal of Psychology, 95, 489-508.

Leder, H., Carbon, C. C., \& Ripsas, A. L. (2006). Entitling Art: Influence of different types of title information on understanding and appreciation of paintings. Acta Psychologica, 121, 176-198.

Maffei, L., \& Fiorentini, A. (1995). Arte e Cervello. [Art and Brain]. Bologna: Zanichelli.

Martindale, C. (1984). The pleasure of thought: A theory of cognitive hedonics. The Journal of Mind and Behaviour, 5, 49-80.

Martindale, C., Moore, K., \& Borkum, J. (1990). Aesthetic preference: Anomalous findings of Berlyne's psychobiological theory. American Journal of Psychology, 103, 53-80.

Millis, K. (2001). Making meaning brings pleasure: The influence of titles on aesthetic experiences. Emotion, 1, 320-329.

Parsons, M. J. (1987). How we are understanding art: A cognitive developmental account of aesthetic experience. Cambridge: Cambridge University Press.

Ramachandran, V. S., \& Hirstein, W. (1999). The science of art. Journal of Consciousness Studies, 6, 15-51.

Reber, R., Schwarz, N., \& Winkielman, P. (2004a). Processing fluency and aesthetic pleasure: Is beauty in the perceiver's processing experience? Personality \& Social Psychology Review, 8, 364-382.

Reber, R., Winkielman, P., \& Schwarz, N. (1998). Effects of perceptual fluency on affective judgments. Psychological Science, 9, 45-48.

Reber, R., Wurtz, P., \& Zimmermann, T. D. (2004b). Exploring "fringe" consciousness: The subjective experience of perceptual fluency and its objective bases. Consciousness and Cognition, 13, 47-60.

Russell, P. A. (2003). Effort after meaning and the hedonic value of paintings. British Journal of Psychology, 94, 99-110.

Russell, P. A., \& Milne, S. (1997). Meaningfulness and hedonic value of paintings: Effects of titles. Empirical Studies of the Arts, 15, 61-73.

Scherer, K. (2003). Introduction: Cognitive components of emotion. In R. J. Davidson (Ed.), Handbook of affective sciences (pp. 563-673). Oxford: Oxford University Press.

Schvaneveldt, R. W., Meyer, D. E., \& Becker, C. A. (1976). Lexical ambiguity, semantic context, and visual word recognition. Journal of Experimental Psychology: Human Perception and Performance, 2, 243-256.

Schwarz, N. (1990). Feeling as information: Informational and motivational functions of affective states. In E. T. Higgins \& R. M. Sorrentino (Eds.), Handbook of motivation and cognition (pp. 527-561). New York: Guilford Press. 
Schwarz, N. (1998). Accessible content and accessibility experiences: The interplay of declarative and experiental information in judgment. Personality and Social Psychology Review, 2, 87-99.

Schwarz, N., \& Clore, G. L. (1983). Mood, misattribution, and judgments of well being: Informative and directive functions of affective states. Journal of Personality and Social Psychology, 49, 513-523.

Silvia, P. J. (2005). Emotional responses to art: From collation and arousal to cognition and emotion. Review of General Psychology, 9, 342-357.

Smith, M. C., Meiran, N., \& Besner, D. (2000). On the interaction between linguistic and pictorial systems in the absence of semantic mediation: Evidence from a priming paradigm. Memory \& Cognition, $28,204-213$.
Whittlesea, B. W. A. (1993). Illusions of familiarity. Journal of Experimental Psychology: Learning, Memory, and Cognition, 19, 12351253.

Winkielman, P., \& Cacioppo, J. T. (2001). Mind at ease puts a smile on the face: Psychophysiological evidence that processing facilitation increases positive affect. Journal of Personality and Social Psychology, 81, 9891000 .

Winkielman, P., Schwarz, N. Fazendeiro, T., \& Reber, R. (2003). The hedonic marking of processing fluency: Implications for evaluative judgement. In J. Musch \& K. C. Klauer (Eds.), The psychology of evaluation: Affective processes in cognition and emotion (pp. 189-217). Mahwah, NJ: Erlbaum, Inc.

Zeki, S. (1999). Inner vision. Oxford: Oxford University Press.

\section{Appendix}

\section{List of Paintings}

Complete List of Selected Paintings, Titles and Title-Painting Matching Agreement Means. Abstract Paintings are Printed in Italics, Representational Paintings in Regular Letters, and Cubist Paintings in Bold Letters

\begin{tabular}{|c|c|c|c|c|c|}
\hline Artist & Year & Original title & Related title & Unrelated title & $\begin{array}{l}\text { Title-picture } \\
\text { matching }\end{array}$ \\
\hline Kirkeby, Per & 1989 & View into the garden I & $\begin{array}{l}\text { Dark Color } \\
\text { Composition }\end{array}$ & $\begin{array}{l}\text { Musician in angular } \\
\text { Facets }\end{array}$ & 4.75 \\
\hline Kline, Franz & 1954 & Painting Number 2 & Black Ladder & Water lilies & 5.00 \\
\hline De Kooning, Willem & 1988 & Untitled & Color Waves & Black Ladder & 4.67 \\
\hline Pollock, Jackson & 1946 & Eyes in the heat & Brushes & Tobacco Pipe & 4.75 \\
\hline Rae, Fiona & 1994 & Untitled & Absent-mindedness & Dancing Band & 4.58 \\
\hline Reichert, Hubertus & 1988 & Untitled & Trial of Blood & $\begin{array}{l}\text { Dolorous } \\
\quad \text { Maidservant }\end{array}$ & 4.83 \\
\hline Rothko, Mark & 1954 & Untitled & Color Surface & Warm and Cold & 5.42 \\
\hline Schumacher, Emil & 1983 & Dark Cloud & Earthy Color & Absent-mindedness & 4.96 \\
\hline Boucher, Francois & 1752 & Reclining Girl & Lying Nude & Color Surface & 5.79 \\
\hline Chardin, Jean-Baptiste-Siméon & 1728 & The Silver Goblet & Classical Still Life & Color Waves & 5.92 \\
\hline Dürer, Albrecht & 1502 & The hare & The hare & Brushes & 3.67 \\
\hline Friedrich, Caspar David & 1821 & Solitary Tree & $\begin{array}{l}\text { Oak tree in wide } \\
\text { open Space }\end{array}$ & Guitar-playing Man & 5.00 \\
\hline Magritte, René & 1929 & This is not a pipe & Tobacco Pipe & The hare & 5.65 \\
\hline Monet, Claude & 1906 & Water lilies & Water lilies & Classical Still Life & 6.33 \\
\hline Gogh, Vincent Van & 1889 & Starry night & The floating sky & Can & 4.79 \\
\hline Warhol, Andy & 1962 & Campbell's Soup & Can & Lying Nude & 5.71 \\
\hline Léger, Fernand & 1916 & Soldier with a pipe & Iron Man & Lady with Fan & 5.63 \\
\hline Picasso, Pablo & 1908 & The friendship & Warm and Cold & Reasoning Man & 4.83 \\
\hline Picasso, Pablo & 1907 & Five woman & Dancing Band & The floating sky & 5.63 \\
\hline Braque, Georges & 1910 & $\begin{array}{l}\text { Portait of Ambroise } \\
\text { Vollard }\end{array}$ & Reasoning Man & $\begin{array}{l}\text { Dark Color } \\
\text { Composition }\end{array}$ & 4.79 \\
\hline Picasso, Pablo & 1921 & Three Musicians & $\begin{array}{l}\text { Musician in } \\
\text { angular Facets }\end{array}$ & $\begin{array}{l}\text { Oak tree in wide } \\
\text { open Spaces }\end{array}$ & 5.21 \\
\hline Picasso, Pablo & 1909 & The queen Isabeau & $\begin{array}{l}\text { Dolorous } \\
\text { Maidservant }\end{array}$ & Iron Man & 5.17 \\
\hline Picasso, Pablo & 1908 & Woman with fan & Lady with Fan & Earthy Color & 5.38 \\
\hline Braque, Georges & 1913 & Woman with a guitar & $\begin{array}{l}\text { Guitar-playing } \\
\text { Man }\end{array}$ & Trial of Blood & 4.92 \\
\hline
\end{tabular}

Received January 1, 2009 Revision received February 25, 2010 